\title{
Tools You Can Trust? Co-design in Community Heritage Work
}

\author{
Simon Popple and Daniel H. Mutibwa
}

\begin{abstract}
This chapter will examine the role of co-design methods in relation to the recent Pararchive Project (http://pararchive.com) that took place between 2013 and 2015 at the University of Leeds. It will draw on the experiences of conducting the project and broader critical frames to examine the nature of collaborative working in the field of cultural heritage and storytelling. It will outline the lessons we have learned from the process and the ways in which the relationships between citizens and cultural institutions are central to working in the heritage sector. It seeks to advocate for the necessity of collaborative methods in the creation of cultural heritage tools that are trusted and adopted by communities.
\end{abstract}

\section{Introduction}

The Pararchive project involved collaboration between a range of communities and two large institutional partners, the Science Museum Group and the BBC Archive. The project developed a platform to facilitate storytelling, research and to provide curatorial tools. It was co-designed and tested by communities in conjunction with academics, curators and technology developers. Using co-production methods in combination with innovative storytelling workshops and creative technology labs, the project demonstrates the necessity of adopting co-working approaches to the problems of cultural heritage curation, engendering democratic encounters with official culture, and developing new partnerships able to consider the challenges of the digital archive. The project resulted in the creation of the new storytelling tool Yarn (http://yarncommunity.com) and offers a series of insights into co-creation

\footnotetext{
S. Popple $(\bowtie) \cdot$ D.H. Mutibwa

University of Leeds, Leeds LS2 9JT, UK

e-mail: S.E.Popple@leeds.ac.uk; D.H.Mutibwa@leeds.ac.uk 
methods, the role of institutional voice, concepts of democratisation of institutional culture, audience, creative intervention and the nature of open digital public space.

\section{$2 \quad$ Nature and Origin of the Project}

The idea for Yarn originated as the result of frustrations encountered on a previous community-based project that had been considering the reuse and repurposing of a series of archived films owned by the BBC relating to the 1984/1985 Miners' strike (Bailey and Popple 2011). This project, Strike Stories, worked with community members drawn from opposing sides in the strike to examine memories and archival materials associated with the strike. In particular it considered issues of the ownership of cultural memory and the desire of participants to directly use archival materials to tell their own stories and add context to what they often felt were misrepresentative materials. The project surfaced a strong community desire to take ownership of cultural resources that represented them and to be able to use them in their own commemorations of difficult events and as a basis for developing their own collective histories. Community members wanted to embrace a clear form of affective labour and work collaboratively with archival institutions to co-curate resources and add their own knowledge and experiences. ${ }^{1}$ Strike Stories offered a strong proof of concept and demonstrated the willingness of citizens to undertake cultural heritage work on their own terms. It also demonstrated the willingness of organisations like the $\mathrm{BBC}$ to work collaboratively to open up resources and explore new models of access and consider issues of copyright and models of community labour or User Generated Content (Popple 2013, 2015).

Nevertheless, within the scope of Strike Stories we were not able to fully realise these aspirations and were limited in time and resources. We were able to facilitate the making of a series of films by project members, which revealed their own interests and concerns and offered a response to the archival record. However we were only able to do this for a very limited number of people and were not able to incorporate original archival elements in their films due to copyright restrictions. Thus in designing the Pararchive project we were keen to draw out these frustrations and work with citizens and cultural institutions to build tools that would allow for mass participation ideally unfettered by copyright restrictions and with an equality of experience and ownership. The potential of participatory media (Jenkins 2006; Jenkins et al. 2006) to allow for greater equality and cross community operability was something we regarded as possessing democratic potential within a specifically configured open cultural space. The aspiration to create a form of genuinely open digital space, based on Habermas's concept of the public sphere, was an attractive but problematic proposition (Cornwall 2008). The digital sphere is only an open space in so far as Internet architectures, governments

\footnotetext{
${ }^{1}$ Details of the project and the Strike Stories films can be accessed here: http://media.leeds.ac.uk/ research/research-projects/strike-stories-films/
} 
and Internet providers allow (Roberts 2009). However we were keen to explore the concept in relation to an 'open space' sitting between citizens and communities on the one hand and cultural institutions on the other. Both traditionally operate in different or restricted digital spheres and through strict protocols. As Dovey has forcefully noted, 'the dynamics of collaboration and exploitation begin to shape new kinds of public space; micro-networks of solidarity, education and intervention' (Dovey 2014, 20).

Citizens are currently invited into institutional spaces, such as museum web spaces, to view and perform certain defined and restricted activities. They may be able to access catalogues, view selected portions of collections and are subject to the institutional interpretive voice. They are often severely limited in what they can do creatively and curatively. Acts of participation, when they are permitted, are solicited, controlled and institutionally framed. Our aspiration was to break through these traditions and protocols. To achieve this we quickly recognised that co-production methods were essential and that we needed to ensure a parity of ownership within the project (Light and Millen 2014). ${ }^{2}$ Using methodologies that are being developed within the AHRC funded Connected Communities Programme and drawing on the experiences of a broad coalition of community research projects we designed the Pararchive project. $^{3}$ The name reflected the concept of a parallel archive, one in which there was an equality of ownership and responsibility for interpretation.

The project, based at the School of Media and Communication at the University of Leeds, subsequently worked with a diverse range of communities to design and build a digital platform that would allow them to tell stories, present their own histories, and research and work collaboratively (Popple 2015). The project team aimed to co-design and build a range of digital resources that could enable communities to develop expertise and resilience. We wanted them to become expert in the telling of their own stories, in communicating their own histories, and sharing knowledge; resilient in developing confidence, forging new communities of interest and affinity, and sharing expertise. We also wanted them to be able to draw on a broad range of archival and cultural materials to facilitate this work. Our groups worked in partnership with academics from Leeds and York University, technology developers from Carbon Imagineering and curators, archivists and IT specialists from the Science Museum Group and BBC Archives to create the new digital resource, Yarn.

Over the course of the eighteen-month project we created a series of tools that were designed to be intuitive and flexible, aiding users to develop projects that incorporated online heritage materials and allowing them to add their own materials in the form of photographs, films, text, and sound recordings. We wanted to orchestrate existing web functions and innovate new tools that would allow people

\footnotetext{
${ }^{2}$ This guide can be downloaded from the Community Media website here: http://www.commedia. org.uk/what-we-do/projects-partners/connected-communities-media-collection/

${ }^{3}$ https://connected-communities.org.
} 
to work on a single site and draw together disparate and unconnected bodies of content. We also wanted to create a space in which every member could create and curate their own collections of materials, and where institutions like galleries and museums could post collections for public use and gather associative data.

Once the communities had determined what they wanted to explore we then engaged a range of institutional partners, most notably the Science Museum Group and $\mathrm{BBC}$ Archives, to begin to provide content and materials to form the basis of these projects and allowed these institutions to explore their own relationships with communities and consider ways in which their content could be published and enhanced through crowdsourcing and public expertise (Boon 2011; Lynch 2011).

The resulting resource Yarn facilitates a number of activities for users and can be summarised in the following manner:

For citizens and communities it means that they can:

1. Tell stories, research cultural and historical themes, create collections, campaign and be creative;

2. Develop links with other people and other communities that share similar interests and concerns;

3. Develop community projects and host collections of community and personal materials including films, photographs and sound files;

4. Keep control of their own intellectual property (IP) by hot linking their own content from third party sites e.g., Historypin, Flickr and Facebook;

5. Explore stories and collections created by other users;

6. Showcase knowledge and personal expertise.

For cultural organisations it means that they can:

1. Feature and promote their collections through the resource without IP transfer;

2. Have access to an open workspace that can create new links to complementary collections and crowd source public expertise;

3. Source content metadata and receive analytics about who is using your content;

4. Run curation or research projects and encourage community use of their digital collections.

For researchers it means that they can access:

1. A set of tools through which to run community projects;

2. A place to feature projects and creative project archives;

3. A means of identifying communities they might want to work with;

4. A collaborative partnership with communities and cultural heritage organisations. 


\section{Co-Design Approaches on the Pararchive Project: Relevant Theoretical Perspectives from Community-Based Participatory Research and Crowdsourcing Literature}

Pararchive was conceived as a highly experimental, explorative and collaborative project from the outset. It was experimental in that it afforded anyone the opportunity to contribute ideas and offer creative input to develop, test and critically engage with the production of Yarn. It was explorative in the sense that it empowered stakeholders to draw on, add, mix and curate resources around shared cultural, historical and thematic interests and affinities from a wide range of sources. From a collaborative vantage point, Pararchive linked local communities with researchers, public cultural institutions, and technology partners concerned with developing collaborative research agendas. It actively fostered the innovation of research practices and knowledge exchange partnerships that continue to develop and expand. ${ }^{4}$ Out of this emerged a range of digital tools and a repository of personal and institutional resources, all of which were researched, co-designed, and evaluated by all project stakeholders that included a wide range of other users. We were guided by the principle that this was a collaborative venture at all levels and that everyone involved had equal status. For example we agreed that any subsequent IP created was equally owned, and that we would evolve post project management structures to direct future developments. ${ }^{5}$

In doing so, Pararchive made effective use of a number of ways of thinking and working that drew on a host of relevant approaches and theoretical perspectives selected from existing literature, especially in the areas of community-based participatory research (CBPR $)^{6}$ and crowdsourcing. To begin with, CBPR-which has its origins in the field of public health especially in the Americas - is understood as a collaborative (and sometimes action-orientated) approach to conducting research

\footnotetext{
${ }^{4}$ New projects have developed between our original communities, including an audience in residence project between the Ceramic City Stories group and the Science Museum in London (See: http://ceramiccitystories.postach.io/page/science-museum) and Island Stories between Brandanii Archaeology and Heritage on Bute and Leeds University to explore the value of cultural heritage tourism facilitated by improved digital connectivity (see: http://www. discoverbutearchaeology.co.uk/?p=992).

${ }^{5}$ The project team are in the process of developing a CIC (Community Interest Company) https:// www.gov.uk/set-up-a-social-enterprise.

${ }^{6}$ It is worth noting that CBPR has been referred to in different terms owing to specific geographical contexts. In North America, for example, it is synonymous with Community-based Participatory Action Research (CBPAR) and Participatory Action Research (PAR). Participatory Development (PD), Participatory Rural Assessment (PRA) and Inclusion Research (IR) appear to be the more commonly applied terms to describe CBPR in the global South while Participatory Community Research (PCR) is one term among many others commonly used in Australia. In the United Kingdom, CBPR is closely associated with the terms Action Research (AR), Community Engagement and Co-production Research. Janes $(2015,2)$ reminds us that whatever the semantic and operational differences these terms/approaches may exhibit, they all demonstrate equitable partnerships bound by a shared commitment to conduct a collaborative enquiry and/or to address a common problem. (Wallerstein and Duran 2008).
} 
on an equal footing amongst academic researchers, community group members, local community organisations and other stakeholders such as local government authorities (Israel et al. 1998; Kindon et al. 2007; Minkler and Wallerstein 2008; Hacker 2013). As Israel et al. (2008, 48) note in their most recent work, the partnerships, "contribute "unique strengths and shared responsibilities" to enhance understanding of a given phenomenon and the social and cultural dynamics of [local communities] and to integrate the knowledge gained with action [geared towards achieving a common goal].'

Both drawing on a synthesis of earlier scholarship and significantly expanding it, Unertl et al. provide a useful summary of the key principles of CBPR based on their recent comprehensive research in the field of health informatics ${ }^{7}$ :

1. Understanding the existing strengths and resources within the community. The community, which has one or more unifying aspects, brings resources to the table. These resources are valued for their unique contribution to the research process;

2. Empowering both academic and community partners through co-learning opportunities, with awareness of social inequalities. Decisions are made in an equitable manner, and activities are planned and implemented collaboratively. Opportunities are made for partners to learn about community needs, strengths, and existing social inequalities;

3. Assisting community-based organisations and community members with building technological and research capacity. The project develops [...] software infrastructures [...] and technological skills. Community members have the opportunity to learn about research processes and methodologies;

4. Building collaborative partnerships in all research phases. The community is not just included during data collection, but rather is included from problem definition through results dissemination. Resources are accorded to partnership building efforts;

5. Defining ownership of technology-related project outputs and planning for technology maintenance. Ensuring that all partners contribute to and agree with plans for technology ownership through all phases of research is important to building trust in partnerships and enabling equitable access to project outputs. Because information and technology needs evolve over time, projects also need to ensure that plans are in place for maintenance of technology products;

6. Viewing research and partnership building as a cyclical and interactive process. Collaboration between researchers and the community is not a 'one-off' activity. Activities related to building and maintaining academic-community partnerships and refinement of research goals occur iteratively;

\footnotetext{
${ }^{7}$ Although the research from which these principles were derived was primarily grounded in the area of public health, the principles can be replicated in other contexts. This replicability informed the co-design approaches adopted on the Pararchive project.
} 
7. Integrating user-centred design or participatory design into CBPR projects. User-centred design and participatory design are complementary approaches to CBPR and integrate well into the iterative, participatory framework developed in CBPR projects;

8. Integrating research results for mutual benefit. The research team builds new knowledge and incorporates the knowledge into action through iterative cycles;

9. Incorporating positive and ecological perspectives into research and technology design/deployment. [...] Technologies should be deployed within, and leverage, trusted social networks;

10. Disseminating knowledge to all partners through multimodal approaches that build technical capacity and provide opportunities for additional [...] research. Presenting knowledge through [accessible] approaches can lead to better understanding of research results and wider dissemination of results in the community (Unertl et al. 2015, 11).

Before we look at how these CBPR principles informed thinking and practice on the Pararchive project, it is necessary to engage with crowdsourcing ${ }^{8}$ - the second co-design approach embraced in the development of Yarn and associated digital tools. Commonly believed to have been coined by Jeff Howe in his Wired Magazine article written in 2006 and subsequently developed further in a series of ensuing articles and book he published in 2009, crowdsourcing has come to be known as a primarily web-based approach by which firms and organisations outsource problem-solving or solicit potentially feasible solutions to specified problems from an ideally diverse crowd via an open call (Howe 2006). The focus of subsequent scholarship has tended to characterise crowdsourcing as a refreshingly different, albeit, exploitative web-based business model situated primarily in business studies and creative industries research (Rossiter 2006; Leimeister et al. 2009; Rouse 2010). However emerging work from other fields and disciplines-such as architecture and planning, information management, and social marketing and health communication - is increasingly making use of the approach to advance respective conceptual underpinnings and practice (Nash 2009; Zhao and Zhu 2012; Parvanta et al. 2013).

More pertinent to our discussion here is the potential use of crowdsourcing as a model for problem solving beyond the business sector, academic disciplines and other professional boundaries (Jones et al. 2008). Of this, Brabham (2008, 75-76) observed that the approach is "distributed beyond the boundaries of professionalism" where 'non-experts' and/or 'amateurs' can contribute creative solutions

\footnotetext{
${ }^{8}$ According to Howe (2009, 280-282), there are several forms of crowdsourcing, namely collective intelligence and/or crowd wisdom, crowd creation, crowd voting, crowd funding and any combination of (some or all of) these. We adopted relevant aspects of collective intelligence (e.g., soliciting comments, views, knowledge and other input from all the Pararchive project stakeholders), crowd creation (i.e., facilitating active engagement in design and discursive processes through the different stages of the project) and crowd voting (seeking stakeholders' judgement and preferences on, say, interface design and language use) Surowiecki (2005). For a general overview of each of the specified forms, visit http://www.crowdsourcing.org/
} 
"toward non-profit applications for health and social and environmental justice" among other areas. One such area is heritage - a sector that has recently witnessed an emergent body of literature on crowdsourcing based on co-curatorial and participatory rather than business transactions (Boon 2011; Owens 2013; Ridge 2013, 2014; Popple 2015). Its deployment within the cultural heritage sector can, we believe, have a more balanced and egalitarian focus and allow for an exchange of expertise and content to create new knowledge. Where the success of crowdsourcing in the business world has hinged on tapping into the knowledge of the recruited 'crowd' in product and service development processes, such success in the heritage sector has manifested itself through the 'crowd's' contribution to adding value to digital cultural heritage collection content (Owens 2013), ultimately improving this for public benefit (Proctor 2013). It is this understanding, particularly its emphasis on the non-exploitative tenets of crowdsourcing, that guided co-design work on the Pararchive project.

Of the ten features or 'rules' Howe (2009) listed that characterise crowdsourcing, we have selected the six that we believe exemplify our approach to collaborative working on Pararchive and emphasise the need to:

1. Pick the right model;

2. Pick the right crowd [or-in the specific context of Pararchive-better rephrased as: identify the relevant stakeholders -for example, local community groups, institutional partners, technologists and research team-to work with];

3. Offer the right incentives;

4. Keep it simple and break it down into easily understandable parts;

5. [Accept that ] [t]he community is always right;

6. Ask not what the crowd [or the selected stakeholders] can do for you, but what you can do for the crowd [or stakeholders] (280-289).

From a conceptual point of view, both CBPR and crowdsourcing as forms of collaborative methodologies, draw on a number of instruments to enhance engagement. In turn, as the argument goes, engagement-if harnessed well-unleashes creativity, energy and optimism in engaged partners. Consequently it lays the foundation of increased interaction, discussion and online and offline action, all of which are crucial aspects in working towards achieving set goals and thereby effecting desired change (Denison and Stillman 2012). This is especially so-as in the case of the Pararchive project-where such collaborative enquiries and problem-solving challenges comprise "designing, developing, managing and interacting with information systems, optimising the use of [digital] technologies and managing [a wide range of content]" (McKemmish et al. 2012, 985). But in practice, it all starts with clearly understanding and defining what the enquiry to be undertaken is seeking to achieve and/or what the problem to be solved is. 
As noted above, the key overarching objective ${ }^{9}$ of the Pararchive project was to co-design and co-produce a new 'open' access digital resource the aim of which was to facilitate engagement with, and use of, public archival resources for storytelling, historical research and creative practice. The thinking was that the resource would enable individuals and local community groups to research and document their histories via the creative linking of their own digital content (film, photographs and other ephemera) with archival material from public institutions such as the BBC and the Science Museum Group (Popple 2011). Crucially this involved us in an extended consideration of the transfer of IP and the copyright implications of collaborative practice and the value of labour in this context (Kennedy 2011). All parties were concerned with ownership of content. On the one hand communities were unwilling to surrender content to large institutions and see their materials ingested on a remote server over which they had no control or right to redress. On the other museums and galleries, often handling third party materials themselves, were concerned with the implications of publishing material not covered by creative commons models-especially when creative re-purposing or re-authoring was an intended consequence of collaborative work.

The outcome of these negotiations was a consensus of working in a context in which there was no direct transfer of IP and in which institutional and private content could be linked from respective third-party sites through the use of hotlinks and orchestrating text and tagging. In a similar manner there was to be a collective approach to the ownership of content created on the site, with full accreditation of the ownership of stories and referenced materials. Authors and content providers retained the right to edit and ultimately remove materials, securing a sense of individual ownership that would engender trust and confidence in the platform and prevent the exploitation of resources and individuals.

Similarly, the recognition of the value of labour in such creative endeavour was crucial to establishing an equality of experience and opportunity. In implementing this consideration it is useful to situate our experience in relation to current critical framings of 'free labour' and exploitative practices often misleadingly presented as mutually rewarding. In his discussion of emergent ecosystems centred on new online collaborative documentary practices, Dovey (2014, 11-32) presents an analysis of critical positions perfectly applicable to other forms of collaborative labour in the cultural heritage sector. Considered within the context of a documentary ecosystem, he argues that assessing who is exploiting whom, is perhaps the wrong question to ask. The assumed inequality of labour and reward predicated by significant post-Marxist critiques is not enough to understand what is happening in new forms of collaborative affective labour, and that a more nuanced understanding is necessary to fully explain engagement and innovation. These he characterises as "new patterns collaboration" that constitute a "new ecosystem" where "the mutuality of exchange creates the value that makes the system itself coherent and

\footnotetext{
${ }^{9}$ For a detailed discussion of the other key overarching aims of the Pararchive project, see Popple (2015).
} 
meaningful" (Dovey 2014, 21). His model of a negotiated and self-defining system of rewards is borne out in our experiences of working with and across communities and in differing practices and aspirations.

Given the complexity of this undertaking in terms of accommodating the varying interests and needs of both local community groups and institutional partners, it was essential to bring on board a technology team that had a vested interest in connecting people from different backgrounds and varying levels of technical capability and digital experience. ${ }^{10}$ Our experienced technology team, assembled through Carbon Imagineering, were drawn from commercial backgrounds and had worked for large multi-nationals such as Orange. They were excited by the prospect of being able to go beyond the traditional practices of responding to pre-determined briefs and being able to work with and for clients who would develop the specification with them. This challenge to orthodox working patterns allowed the Carbon team to explore new ways of working and helped define the innovation of the technology lab model that characterised their working practice with our parent communities. Likewise, it was important that a research team was assembled thatfor the most part—shared the affinities and agendas of the rest of the project stakeholders.

As noted in Mutibwa and Philip (2014), four local community groups ${ }^{11}$ situated in three different regions in the U.K. were at the heart of Pararchive. In line with the aim of enabling storytelling, historical research and creative practice, two of these (Brandanii Archaeology and Heritage and Ceramic City Stories) — based on the Isle of Bute in Scotland, and Stoke-on-Trent respectively-were heritage-focused while the other two (Arduino MCR and Bokeh_Yeah!) both from Manchester were more creative and technology-orientated. Although the groups exhibited different foci, the one aspect that they shared in common was that they actively engaged with issues in their respective locales that mattered to them based on the extensive local knowledge and social networks that they possessed. These factors-coupled with the geographical spread-rendered them suitable for collaboration.

Through regular technology laboratory workshops over an eighteen-month period, Carbon Imagineering, along with the research team, worked with the respective community groups to identify any storytelling and historical research projects that individual members were interested in pursuing and where possible, to look for connections among these. An early indication of the potential of this approach emerged in the joint interests between our Bute and Stoke-on-Trent

\footnotetext{
${ }^{10}$ Digital inclusivity was a driving concern and led to the development of the supplementary Island Stories Project. http://www.buteman.co.uk/what-s-on/leisure/leeds-team-in-bute-digitalheritage-visit-1-3554161.

${ }^{11}$ Visit the following links for more information about each of the four community groups: http:// www.discoverbutearchaeology.co.uk/; http://ceramiccitystories.org/about; https://www.facebook. com/ArduinoMCR; https://www.facebook.com/BokehYeah.
} 
groups that centred on industrial archaeology and ceramics history. ${ }^{12}$ As observed elsewhere and in alignment with CBPR principles, the initial workshops were designed to:

build good working relationships and chemistry with the four Pararchive community groups in the co-design lab workshops we held, something that was instrumental in helping us listen to group members' research interests and affinities, understand their aspirations and motivations, and support them [...] to tell their stories (Mutibwa 2014, no pagination).

Out of these early conversations arose the input used to design the initial interactive prototype versions of Yarn as well as recurrent themes that centred around "archaeology, dairy farming, conservation of natural resources and landscapes, wildlife, urban greening, genealogy, ceramics and pottery, reminiscence and memory, digital and music heritage, as well as the exploration and digitisation of archives" (Mutibwa and Philip 2015, 4).

Ensuing workshops concentrated on two main aspects, namely story-building exercises; and prototype testing. The former involved structuring stories in the form of blocks or events (metadata about dates, places, people), artefacts (which enrich/ support the story, for example, photographs, audio-visual content) and connectors (which link the blocks/events together) while the latter comprised inviting project stakeholders and numerous potential external users and groups to test the early interactive prototypes for functionality and suitability (Mutibwa and Philip 2014). In tune with the outlined CBPR principles and crowdsourcing rules above, this move helped integrate key aspects of user-centred design and/or participatory design, especially as far as the prototyping workshops and functionality evaluations of users were concerned. During the various co-production and development phases of Yarn, the Carbon team put in practice what it preached by responding positively to the needs, anxieties and preferences of the broad range of potential users, thereby ensuring that Yarn became a truly and easily navigable resource for the wider public to use.

\section{$4 \quad$ Case Study}

To understand how we applied these principles we will briefly consider Ceramic City Stories group (CCS) based in Stoke-on-Trent as an illustrative example. CCS members identify, explore, and tell stories about the people, culture, buildings and urban environment that continue to define Stoke-on-Trent as the unique ceramic

\footnotetext{
${ }^{12}$ Our communities developed new relationships, identifying common interests, and began working together and sharing knowledge and resources. For example, the famous Victorian toilets on the key side at Rothesay on Bute were manufactured in Stoke-on Trent and an exchange soon began between these two distant communities about its history and shared heritage. A tweeted photograph of the toilet ceramics was almost immediately responded to with information about the ceramic and a picture of the factory in which it was made several hundred miles away. http://www. bute.me/victoriantoilets/
} 
city. Often revealing a local, national and even international context, the stories span at least three centuries and recount the history of the Potteries with a particular focus on coal mining, on the production of distinct ceramic ware (e.g., cutlery, vases, jars), and on heavy clay products (e.g., tiles, chimney pots). Furthermore, the stories engage with how associated traditions, customs, values, practices and myths have become inextricably intertwined with the lives, identity, and memory of the people from Stoke over time. Within the context of Pararchive, we explored the stories that community members wanted to tell, identified artefacts they wanted or needed to use to support the stories, and examined possible connections between the stories.

One such story wove together family and working life history in the Potteries. It told the story of a woman who- as an eleven year-old along with her family-was evacuated from London during the Blitz and relocated to the Potteries. Research into her life conducted by her daughter-and a CCS member-drew on a range of sources: anecdotal accounts and experiential knowledge of fellow group members within the community lab workshops; conversations with family members and other people from the Potteries who knew and worked with her; family photo albums; archived logbooks at the school she attended; local history websites; audio-visual content provided by the BBC through Box of Broadcasts; as well as inspiration from and access to a wide range of medical, ceramic and sanitary ware collections stored at the Science Museum but originating in the Potteries.

The family and working life details that she gathered about the period of her mother's past were new to her and she had been unaware of them until beginning work on Pararchive. This story is only one among many that highlight the energy and commitment to engagement with cultural heritage resources on Pararchive and played a key role in shaping and influencing the co-design of Yarn at all levels.

\section{$5 \quad$ Institutional Spaces and Co-working}

The success of the project primarily rested with our community partners, but was strengthened and guided by the support of the project's institutional partners- the Science Museum Group and the BBC Archive. Their provision of expertise ${ }^{13}$ and content not only helped enrich many of the storytelling and historical research projects, but it also provided a model through which local communities and public cultural institutions could reconfigure the ways in which they relate to each other with a view to maintaining long-lasting collaborative partnerships. Public cultural organisations now recognise the role that the differently-situated local community groups and interested members of the wider public can play in adding value to historical and cultural assets in a way that ensures the on-going relevance of such

\footnotetext{
${ }^{13}$ See Popple (2015) for an exploration of possible models that could help address perceived contentious issues around third party rights and licensing agreements particularly as they relate to project work emanating from community-institutional partnerships.
} 
assets. This recognition of and openness to collaborative engagement-as prescribed by some of the specified CBPR principles and crowdsourcing rules above-have facilitated the creation of a digital space where shared community and institutional affinities and agendas are nurtured and in which different sets of knowledge are co-produced to enhance public engagement with our common heritage. In doing so, concerns and questions often raised about power dynamics and control stacked in favour of either academic researchers or institutional partners are disproved, meaning that equitable partnerships can be achieved more often if sufficient time and effort is invested.

Our approach to the project was guided by looking at a key series of problems we felt communities and cultural organisations experience in relation to using online heritage resources and in developing such collaborative relationships. We felt that issues of access, copyright, and the restrictions often placed on usage were compounded by existing problems of web usability and the dispersed nature of existing resources and platforms. The project team was particularly keen to encourage the direct use of digital archives in creative work and historical research and at the same time examine how to break down the barriers between institutional collections (both geographic and administrative) and the publics they served (Adair et al. 2011). Both organisations were similarly focussed on the challenges of changing the nature of the relationships they enjoyed with existing public audiences and in developing new and mutually beneficial alliances.

In the first case the BBC, as a directly publicly funded national and international organisation, has a public service remit regularly renewed by government. ${ }^{14}$ It has been accused of being patrician and in enjoying a difficult relationship with audiences in terms of access to its vast archive of heritage resources and in the ability of those who have funded its acquisition to view and use materials (Weissmann 2013). It was keen to explore new models of collaboration and to try and resolve some of the issues around copyright and IP transfer, especially of third party materials, and engage the audience in the collaborative management of some of its resources through crowd funding and creative initiatives. It had made initial steps through projects relating to specific archive areas such as its Word Service programme collection and via the Digital Space initiative. ${ }^{15}$ By thinking more conceptually we were able to develop a model (which now needs to be tested) in which we move away from the historical model of the BBC's audience as viewers and listeners, receptors for content, to become active and equal participants. In conjunction with Tony Ageh, BBC Head of Archive Development, we proposed the concept of citizen 'animateurs', citizens who can:

play an increasingly integrated role in many of the fundamental functions of the archive and engage in a range of creative, research and storytelling activities that are no longer limited

\footnotetext{
${ }^{14}$ The current BBC Charter is due to be renewed in 2016 and is proving extremely controversial.

${ }^{15}$ See Kiss, Jemima. A digital public space is Britain's missing national institution. http://www. theguardian.com/technology/2015/mar/05/digital-public-space-britain-missing-national-institution.
} 
or constrained by traditional anxieties about the ceding of power and the retention of a lone authoritative voice (Popple 2015, 137).

The Science Museum group were similarly concerned with reaching new audiences and developing models of collaborative practice which extended beyond local communities and visitors to their four museums based in the cities of London, Manchester, Bradford and York. What was also particularly problematic, and frustrating, was the barrier that existed between people and non-digital materials - objects and images - in a physical archival space. Collections, such as those owned by the Science Museum, were extremely attractive to communities but they felt remote and disadvantaged. One initiative, which has now grown into a follow-on research project of its own, saw us taking community volunteers from Stoke-on-Trent into the Science Museum archive to explore and select from one of the most valuable scientific collections in the world relating to their interest in ceramics. During this intensive weekend our community partners were given behind-the-scenes access to Blythe House, the Science Museum's object store, and encouraged to access and explore more than 170,000 artefacts not on public display. Working with curators they photographed objects of interest and we are now building a 3D visualization of the archive and developing hyperlinks to allow for greater access and ownership of public collections. ${ }^{16}$ The potential for creating an open and engaging space is evidenced through this community in residence project and provides a model of communities that coalesce around issues of common interest, shared aspiration and collaborative solidarity. Thus, this small example exemplifies the value of public institutional collaboration, and is emblematic of the project and its future potential to bring communities and institutions together in mutually reinforcing relationships as we seek to take it to the next phase.

\section{Conclusions and Reflections}

The question of trust, both in terms of the development of collaborative relationships and the resultant tool, and the value of labour and collective experience, is what ultimately guarantees the success or failure of this, or indeed any, collaborative project. Although its first phase is now complete we are developing new threads of research and strengthening relationships that have developed throughout its course. Ultimately we will be judged on the long-term success of the resource we have co-created, but in the interim the knowledge and reflective platform it has allowed us has generated a series of useful conclusions we now want to summarise and hope will prove useful for new projects and collaborative ventures in the field of cultural heritage research.

\footnotetext{
${ }^{16}$ See a prototype here: http://tomjackson.photography/interactive/blythehouse.html?html5=prefer. We are also examining the potential of developing $3 \mathrm{D}$ patterns for remote community printers to address issues of embodiment and materiality.
} 
1. The project has demonstrated the need for a commitment to partnerships between communities (defined in their broadest sense) and institutional partners to develop digital interfaces to facilitate co-curation, creative exploitation, and shared copyright models that open up cultural resources and normalise relations in open digital space. It has highlighted the need for openness, honesty, and the ability to listen as well as speak. It has highlighted the value of recognising where expertise resides and of the importance of plural voices.

2. It examined the role of co-creation within this developmental context and highlights the importance of current approaches to the problems of liberating cultural resources from formally closed and often remote institutions. This is a necessary, democratic, and moral undertaking.

3. It has also examined the tensions between different cultural sectors and drawn on the experiences of institutional partners interested in exploring these approaches as a means of reaching out to new audiences and allowed public expertise to inform knowledge about their collections. Above all, it highlighted the need to negotiate and recognise mutual needs, and acknowledge barriers such as copyright that are often beyond the control of partners. Crucially, it evidences the need to identify and value cultural labour in all its forms, and to respect mutual boundaries.

4. It has demonstrated the potential of developing social cohesion through collaborative working and collaborative storytelling predicated on shared cultural understanding and shared cultural heritage resources. ${ }^{17}$ It has shown the cumulative strength of working together to achieve commonly identified goals with clearly set expectations. (Cameron and Kenderdine 2010)

5. Finally, it demonstrated the importance of openness, of the recognition of different levels of engagement, of different literacies, and of the value of mutual respect across communal and institutional boundaries.

As we continue to reflect on our immediate experiences there is much we would do differently in any future project. But we have only come to this realisation through the experience of collaborative working and from learning from all our partners. Collaborative working is deeply rewarding and continually challenges critical assumptions and models of practice and is thus essential as a consequence.

Open Access This chapter is distributed under the terms of the Creative Commons AttributionNoncommercial 2.5 License (http://creativecommons.org/licenses/by-nc/2.5/) which permits any noncommercial use, distribution, and reproduction in any medium, provided the original author(s) and source are credited.

\footnotetext{
${ }^{17}$ One of the most memorable experiences was working with communities to discover what they were passionate about and what they wanted to explore through their own storytelling. This passion and expertise was infectious and as the project progressed communities developed new relationships, identifying common interests, and began working together and sharing knowledge and resources. The famous Victorian toilets alluded to earlier represent an illustrative example among many.
} 
The images or other third party material in this chapter are included in the work's Creative Commons license, unless indicated otherwise in the credit line; if such material is not included in the work's Creative Commons license and the respective action is not permitted by statutory regulation, users will need to obtain permission from the license holder to duplicate, adapt or reproduce the material.

\section{References}

Adair, B., Filene, B., \& Koloski, L. (Eds.). (2011). Letting go? Sharing historical authority in a user-generated world. Philadelphia: The Pew Center for Arts \& Heritage.

Bailey, M., \& Popple, S. (2011). The 1984/85 miners' strike: Re-claiming cultural heritage. In L. Smith, P. Shackel, \& G. Cambell (Eds.), Heritage, labour and the working classes (pp. 19-33). London: Routledge.

Boon, T. (2011). Co-curation and the public history of science and technology. Curator: The Museum Journal, 54(4), 383-387.

Brabham, D. C. (2008). Crowdsourcing as a model for problem-solving. Convergence: The International Journal of Research into New Media Technologies, 14(1), 75-90.

Cameron, F., \& Kenderdine, S. (Eds.). (2010). Theorizing digital cultural heritage. Boston: MIT Press (Media in Transition).

Cornwall, A. (2008). Democratising engagement: What the UK can learn from international experience. Demos. Retrieved January 9, 2015, from http://www.demos.co.uk/files/ Democratising_Engagement-web.pdf.

Denison, T., \& Stillman, L. (2012). Academic and ethical challenges in participatory models of community research. Information, Communication \& Society, 15(7), 1037-1054.

Dovey, J. (2014). Documentary ecosystems: Collaboration and exploitation. In K. Nash et al. (Eds.), New documentary ecologies: Emerging platforms, practices and discourses (pp. 11-32). Basingstoke, England: Palgrave Macmillan.

Hacker, K. (2013). Community-based participatory research. Thousand Oaks, CA: Sage.

Howe, J. (2006). The rise of crowdsourcing. Wired Magazine. Retrieved July 28, 2015, from http:// archive.wired.com/wired/archive/14.06/crowds.html.

Howe, J. (2009). Crowdsourcing: Why the power of the crowd is driving the future of business. New York: Palgrave McMillan.

Israel, B. A., Schulz, A. J., Parker, E. A., \& Becker Adam, B. (1998). Review of community-based research: Assessing partnership approaches to improve public health. Annual Review of Public Health, 19, 173-202.

Israel, B. A., Schulz, A. J., Parker, E. A., Becker, A. B., Allen, A., III, \& Guzman, R. J. (2008). Critical Issues in Developing and Following CBPR Principles. In M. Minkler \& N. Wallerstein (Eds.), Community-based participatory research for health: From process to outcomes (2nd ed., pp. 47-66). San Francisco, CA: Jossey-Bass.

Janes, J. E. (2015). Democratic encounters? Epistemic privilege, power, and community-based participatory action research. Action Research, 1-16. doi:10.1177/1476750315579129.

Jenkins, H. (2006). Convergence culture: When old and new media collide. New York: New York University Press.

Jenkins, H., Purushotma, R., Weigel, M., Clinton, K., \& Robison A. J. (2006). Confronting the challenges of participatory culture: Media education for the 21 st century. Retrieved January 9, 2015 from http://henryjenkins.org/2006/10/confronting_the_challenges_of.html.

Jones, L., Koegel, P., \& Wells, K. B. (2008). Bringing experimental design to communitypartnered participatory research. In M. Minkler \& N. Wallerstein (Eds.), Community-based participatory research for heatlh: From process to outcomes (2nd ed., pp. 65-85). San Francisco, CA: Josey-Bass. 
Kennedy, H. (2011). Net work: Ethics and values in Web design. Basingstoke, England: Palgrave Macmillan.

Kindon, S., Pain, R., \& Kesby, M. (Eds.). (2007). Participatory action research approaches and methods: Connecting people, participation and place. London: Routledge.

Leimeister, J. M., Huber, M., Bretschneider, U., \& Krcmar, H. (2009). Leveraging crowdsourcing: Activation-supporting components for IT-based ideas competitions. Journal of Management Information Systems, 26(1), 197-224.

Light, A., \& Millen, T. (2014). Making media with communities: Guidance for researchers. Newcastle, England: University of Northumbria.

Lynch, B. (2011). Whose cake is it anyway? A collaborative investigation into engagement and participation 12 Museums and galleries in the UK. London: Paul Hamlyn Foundation. Retrieved January 9, 2015 from http://www.phf.org.uk/publications/whose-cake-anyway/

McKemmish, S., Burstein, F., Faulkhead, S., Gilliland, A., McLouglin, I., \& Wilson, R. (2012). Working with communities. Information, Communication \& Society, 15(7), 985-990. doi:10. 1080/1369118X.2012.711846.

Minkler, M., \& Wallerstein, N. (Eds.). (2008). Introduction to CBPR: New issues and emphases. In community-based participatory research for health: From process to outcomes ( $2 \mathrm{nd}$ ed., pp. 5-23). San Francisco, CA: Jossey-Bass.

Mutibwa, D. H. (2014). Pararchive participates in the 2014 ESRC festival of social science. The Pararchive Project Website. Retrieved 4 August, 2015, from http://pararchive.com/2014/11/ 13/pararchive-participates-in-the-2014-esrc-festival-of-social-science/

Mutibwa, D. H., \& Philip, F. (2014). Open access-Digital communities. Viewfinder: The Journal of the British Universities Film \& Video Council, 97, 10-11.

Mutibwa, D. H., \& Philip, F. (2015). Reflections from within Pararchive's engine room. Connecting Communities: A Pararchive Project Journal, 4.

Nash, A. (2009, November 14). Web 2.0 applications for improving public participation in transport planning. Vienna, Austria: Vienna Transport Strategies.

Owens, T. (2013). Digital cultural heritage and the crowd. Curator: The Museum Journal, 56(1), 121-130.

Parvanta, C., Roth, Y., \& Keller, H. (2013). Crowdsourcing 101: A few basics to make You the leader of the pack. Health Promotional Practice, 14(2), 163-167. doi:10.1177/ 1524839912470654.

Popple, S. E. (2011). 'It's not really our content': Archiving media history in the digital Age". In W. P. David, N. Jankowski, \& S. Jones (Eds.), The long history of new media: Technology, historiography, and newness contextualized. Digital formations (pp. 317-332). New York: Peter Lang.

Popple, S. E. (2013). The new golden age? using UGC to develop the public digital space". In S. Popple \& H. Thornham (Eds.), Content cultures: Transformations of user generated content in public service broadcasting (pp. 131-149). London: I.B.Tauris.

Popple, S. E. (2015). The new Reithians: Pararchive and citizen animateurs in the BBC digital archive. Convergence: The International Journal of Research into New Media Technologies, 21(1), 132-144.

Proctor, N. (2013). Crowdsourcing-An introduction: From public goods to public good. Curator: The Museum Journal, 56(1), 105-106.

Ridge, M. (2013). From tagging to theorising: Deepening engagement with cultural heritage through crowdsourcing. Curator: The Museum Journal, 56(4), 435-450.

Ridge, M. (2014). Crowdsourcing our cultural heritage: Introduction. In M. Ridge (Ed.), Crowdsourcing our cultural heritage (pp. 1-14). Surrey, England: Ashgate.

Roberts, B. (2009). Beyond the 'networked public sphere': Politics, participation and technics in Web 2.0. Fibre Culture Journal, 14. Retrieved January 9, 2015, from http://fourteen. fibreculturejournal.org/fcj-093-beyond-the-networked-public-sphere-politics-participation-andtechnics-in-web-2-0/ 
Rossiter, N. (2006). Organised networks: Media theory, creative labour, new institutions. Rotterdam, The Netherlands: NAI.

Rouse, A. C. (2010). A preliminary taxonomy of crowdsourcing. ACIS 2010 Proceedings. Paper 76. Retrieved January 27, 2015, from http://aisel.aisnet.org/acis2010/76.

Surowiecki, J. (2005). The wisdom of crowds. New York: Anchor Books.

Unertl, K. M., Schaefbauer, C. L., Campbell, T. R., Senteio, C., Siek, K. A., Bakken, S., et al. (2015). Integrating community-based participatory research and informatics approaches to improve the engagement and health of underserved populations. Journal of the American Medical Informatics Association, 1-15. doi:10.1093/jamia/ocv094.

Wallerstein, N., \& Duran, B. (2008). The theoretical, historical, and practice roots of CBPR. In M. Minkler \& N. Wallerstein (Eds.), Community-based participatory research for health: From process to outcomes (2nd ed., pp. 25-46). San Francisco, CA: Jossey-Bass.

Weissmann, E. (2013). The BBC and the limits of UGC: Some afterthoughts. In S. Popple \& $\mathrm{H}$. Thornham (Eds.), Content cultures: Transformations of user generated content in public service broadcasting (pp. 199-213). London: I.B. Tauris.

Zhao, Y., \& Zhu, Q. (2012). Evaluation on crowdsourcing research: Current status and future direction. Information Systems Frontiers, 16, 417-434. 